\title{
Studi Anomali Gayaberat Free Air di Kota Surabaya
}

\author{
Enira Suryaningsih dan Ira Mutiara Anjasmara \\ Departemen Teknik Geomatika, Fakultas Teknik Sipil dan Perencanaan, Institut Teknologi Sepuluh Nopember (ITS) \\ e-mail:ira@geodesy.its.ac.id
}

\begin{abstract}
Abstrak-Model Geoid Global EGM (Earth Gravitational Model) 2008 merupakan model geoid yang didapatkan dari informasi anomali gayaberat free-air dengan grid 2.5 menit. Grid tersebut dibentuk dari kombinasi data terestrial, turunan altimetri dan data gayaberat dari airborne. Akan tetapi, pengukuran gayaberat di Indonesia masih jarang dilakukan hingga saat ini dan kontribusi nilai gayaberat untuk EGM 2008 di Indonesia kurang. Oleh karena itu, tujuan dalam penelitian ini yaitu untuk mengetahui anomali gayaberat free air di Kota Surabaya berdasarkan pengukuran data insitu serta data anomali gayaberat free air EGM 2008. Metodologi penelitian studi ini yaitu dengan pengambilan data insitu di Kota Surabaya, kemudian diolah menjadi anomali gayaberat free air. Data tersebut di-plotting menggunakan aplikasi Generic Mapping Tools. Data anomali gayaberat free air dari EGM 2008 juga diplotting menggunakan GMT. Berdasarkan pengolahan dan analisis data insitu didapatkan bahwa nilai anomali gayaberat free air berkisar antara $-25 \mathrm{mGal}-20 \mathrm{mGal}$. Sedangkan nilai anomali gayaberat free air dari EGM 2008 berkisar antara -30 mGal - 10 mGal.
\end{abstract}

Kata kunci-Data Insitu, EGM 2008, Anomali Gayaberat Free Air.

\section{PENDAHULUAN}

$\mathrm{T}$ EKNOLOGI GNSS (Global Navigation Satelite System) merupakan teknologi survei dan pemetaaan yang memiliki peran penting saat ini. Teknologi GNSS dapat digunakan untuk menentukan posisi tiga dimensi dengan beracuan pada ellipsoid global yaitu WGS 84. Ellipsoid merupakan model matematis bumi [1] yang digunakan untuk mempermudah perhitungan matematis di atas permukaan bumi. Informasi tinggi yang dihasilkan dari pengukuran tersebut disebut tinggi normal atau tinggi ellipsoid. Akan tetapi, informasi tinggi tersebut tidak dapat dijadikan sebagai acuan informasi tinggi karena tidak menggambarkan kondisi fisik bumi yang sebenarnya. Informasi tinggi yang dibutuhkan seharusnya beracuan pada geoid atau biasa disebut tinggi ortometrik.

Geoid merupakan model fisik bumi yaitu model bumi yang paling mendekati bentuk bumi yang sebenarnya. Model fisik bumi tersebut diasumsikan sama atau berhimpit dengan tinggi muka laut rata-rata (Mean Sea Level/MSL) pada kondisi laut yang tenang [1]. Penentuan geoid adalah penentuan penyimpangan geoid atau undulasi geoid $(\mathrm{N})$ dan defleksi vertikal $(\xi)$ terhadap elipsoid referensi. Nilai undulasi geoid tidak pernah sama disetiap tempat, hal tersebut disebabkan ketidakseragaman sebaran densitas bumi. Nilai undulasi geoid tersebut yang digunakan untuk memodelkan bentuk geoid yang sebenarnya [2].
Pemodelan potensial gravitasi bumi yang akurat secara global dengan resolusi tinggi merupakan hal yang mendasar dalam bidang geodesi, geofisika, oseanografi dan berbagai aplikasinya[3]. Hingga saat ini sudah banyak terdapat model geoid global, salah satunya adalah EGM 2008 (Earth Gravitational Model 2008). Model Geoid Global EGM 2008 merupakan model geoid yang didapatkan dari informasi anomali gayaberat free-air dengan grid 2.5 menit. Grid tersebut dibentuk dari kombinasi data terestrial, turunan altimetri dan data gayaberat airborne [3].

Pengukuran gayaberat di Indonesia masih jarang dilakukan hingga saat ini. Pengukuran gayaberat memiliki manfaat yang beragam salah satunya adalah diketahuinya anomali gayaberat free air. Anomali gayaberat free air merupakan nilai anomali gayaberat yang telah dikurangi efek udara bebas sehingga dapat merepresentasikan topografi suatu area secara umum. Oleh karena itu, dalam penelitian ini dilakukan pengukuran gayaberat untuk mengetahui anomali gayaberat free air di Kota Surabaya berdasarkan insitu dan data EGM 2008.

\section{METODOLOGI PENELITIAN}

\section{A. Lokasi Penelitian}

Lokasi penelitian dalam penelitian studi ini yaitu di Kota Surabaya. Secara geografis Kota Surabaya berada di $7^{\circ} 9^{\prime}$ $7^{\circ} 21^{\prime}$ LS dan $112^{\circ} 36^{\prime}$ - $112^{\circ} 57^{\prime}$ BT. Peta lokasi penelitian dapat dilihat pada Gambar 1.

\section{B. Data dan Peralatan}

1) Data

Data yang digunakan dalam studi dibagi menjadi dua, yaitu data primer dan data sekunder. Data primer dalam studi ini adalah gayaberat Kota Surabaya hasil pengukuran tahun 2017. Sedangkan data sekundernya adalah anomali gayaberat free air EGM 2008 dan gayaberat Kota Surabaya hasil pengukuran tahun 2016.

\section{2) Peralatan}

Perlatan yang digunakan pada penelitian ini meliputi:

1. Perangkat Keras

a. Gravimeter Lacoste \& Romberg tipe G-1053

b. GPS Geodetik

2. Perangkat Lunak

a. Aplikasi Generic Mapping Tool (GMT)

b. Aplikasi Pengolah Angka dan Kata 


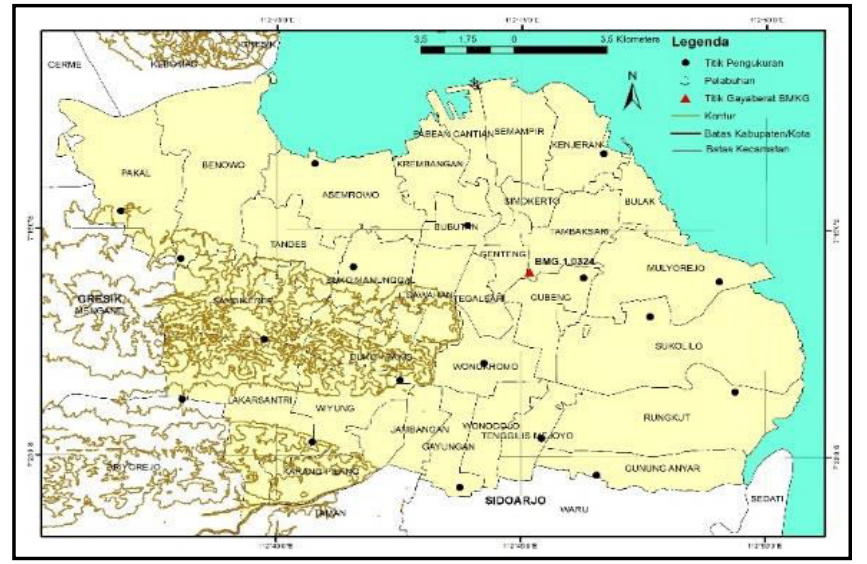

Gambar 1. Lokasi Penelitian .

\section{Tahapan Pengolahan Data}

Tahapan pengolahan data pada penelitian ini adalah sebagai berikut:

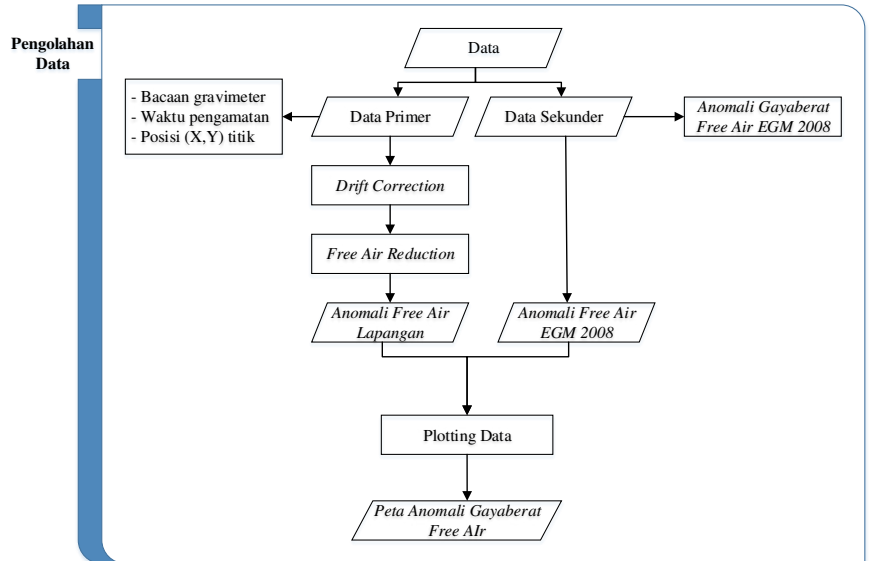

Gambar 2. Diagram Alir Pengolahan Data.

Penjelasan diagram alir di atas sebagai berikut.

\section{1) Konversi Bacaan}

Nilai bacaan alat di lapangan perlu dikonversi dalam satuan mGal. Proses konversi nilai menggunakan tabel konversi yang disediakan. Perumusan yang digunakan dalam konversi adalah sebagai berikut [4]. (1)

hasil $=\{($ bacaan-counter $) x$ faktor interval $\}+$ value in $m G a l$

\section{2) Drift Correction}

Koreksi ini dilakukan untuk menghilangkan pengaruh perubahan kondisi alat terhadap nilai bacaan. Koreksi ini dilakukan dengan cara melakukan pengkuran dengan metode looping, sehingga nilai penyimpangannya diketahui. Besarnya koreksi apungan dirumuskan sebagai berikut [5].

$$
D C=-\frac{g_{A}^{\prime}-g_{A}}{t_{A}^{\prime}-t_{A}}\left(t_{n}-t_{A}\right)
$$

Keterangan:

$D C \quad$ : koreksi apungan pada titik acuan pengamatan

$g_{A} \quad:$ harga gayaberat di titik acuan pada waktu

$t_{A} g_{A}^{\prime}$ : harga gayaberat di titik acuan pada waktu $t^{\prime}$
$t_{A} \quad:$ waktu pengamatan di titik acuan saat awal

$t_{A}^{\prime} \quad$ : waktu pengamatan di titik acuan saat akhir

$t_{n} \quad$ : waktu pengamatan di titik pengamatan

\section{3) Free Air Reduction}

Reduksi udara bebas dilakukan untuk mengurangi efek atmosfer di atas permukaan tanah. Massa di atas geoid diabaikan kecuali yang linier sehingga didapatkan [6],

$$
F=-\frac{\partial \mathrm{g}}{\partial \mathrm{H}} H=0.3086 H
$$

Keterangan:

$$
\begin{array}{ll}
F & \text { : nilai reduksi udara bebas } \\
H & \text { : tinggi ortometrik }
\end{array}
$$

Untuk mengetahui nilai anomali gayaberat free air dibutuhkan juga nilai gayaberat normal yaitu nilai gayaberat pada ellipsoid. Untuk mendapatkan nilai tersebut formula Somagliana yang digunakan sebagai berikut [6]

$$
\gamma_{(\varphi)}=\frac{a \gamma_{a} \cos ^{2} \varphi+b \gamma_{b} \sin ^{2} \varphi}{\sqrt{a^{2} \cos ^{2} \varphi+b^{2} \sin ^{2} \varphi}}
$$

dimana,

$\varphi$ : lintang titik (derajat)

$a$ : sumbu panjang ellipsoid (m)

$b$ : sumbu pendek ellipsoid (m)

$\gamma_{a}$ : gayaberat normal di ekuator (mGal),

$$
\gamma_{a} \text { WGS } 84=9780325,3359 \mathrm{mGal}
$$

$\gamma_{b}$ : gayaberat normal di kutub (mGal),

$\gamma_{b}$ WGS $84=9832184,9378 \mathrm{mGal}$

Untuk mengetahui hubungannya dengan elevasinya maka digunakan deret Taylor sebagai berikut ${ }^{[6]}$

$$
\begin{gathered}
\gamma_{(h)}=\gamma_{(\varphi)}\left[1-2\left(1+f+m-2 f \sin ^{2} \varphi\right) \frac{H}{a}+3 \frac{H^{2}}{a^{2}}\right] \\
m=\frac{\omega^{2} a^{2} b}{G M}
\end{gathered}
$$

dimana,

$\gamma_{(h)}$ : gayaberat normal pada lintang $\varphi$ dan tinggi $h$ (mGal)

$\gamma_{(\varphi)} \quad$ : gayaberat normal pada lintang $\varphi(\mathrm{mGal})$

$\varphi \quad$ : lintang titik (derajat)

$f \quad$ : penggepengan ellipsoid

$m \quad$ : perbandingan percepatan sentrifugal dan gravitasi pada ekuator

$H \quad$ : tinggi ortometrik (m)

$a \quad$ : sumbu panjang ellipsoid (m)

$b \quad:$ sumbu pendek ellipsoid (m)

$\omega \quad$ : percepatan sudut bumi, $\omega$ WGS $84=7292115 \times 10^{-11} \mathrm{rad} / \mathrm{s}$

GM : konstanta gravitasi geosentrik bumi $G M$ WGS $84=3986004,418 \times 10^{8} \mathrm{~m}^{3} \mathrm{~s}^{-2}$

Nilai anomali gayaberat free air didapatkan dengan

dimana,

$$
\Delta g=g_{o b s}-\gamma_{(h)}+F
$$

$\Delta g \quad$ : anomali gayaberat free air (mGal)

$g_{\text {obs }} \quad$ : gayaberat geoid/pengamatan $(\mathrm{mGal})$ 
4) Plotting Data

Penyajian data dilakukan dengan melakukan plotting anomali gayaberat free air pada aplikasi GMT.

\section{HASIL DAN ANALISIS}

\section{A. Konversi Bacaan}

Hasil pengukuran gayaberat relatif di lapangan menghasilkan nilai bacaan alat yang perlu dikonversi menggunakan formula 1. Hasil pengukuran tersebut dapat dilihat pada tabel 1 .

Tabel 1.

Bacaan Alat

\begin{tabular}{cccccc}
\hline \hline Stasiun & $\begin{array}{c}\text { Bacaan } \\
1\end{array}$ & Bacaan 2 & Bacaan 3 & Rata-rata & $\begin{array}{c}\text { Std. } \\
\text { Dev }\end{array}$ \\
\hline BMG.1.0324 & 1719.030 & 1719.030 & 1719.030 & 1719.030 & 0 \\
BM 16 & 1719.255 & 1719.300 & 1719.290 & 1719.282 & 0.024 \\
LB06 & 1726.005 & 1726.005 & 1726.005 & 1726.005 & 0 \\
BM01 & 1713.372 & 1713.372 & 1713.372 & 1713.372 & 0 \\
LB04 & 1706.440 & 1706.440 & 1706.440 & 1706.440 & 0 \\
SBY007 & 1714.222 & 1714.222 & 1714.222 & 1714.222 & 0 \\
BM33 & 1711.520 & 1711.520 & 1711.520 & 1711.520 & 0 \\
BM29 & 1714.141 & 1714.141 & 1714.141 & 1714.141 & 0 \\
BM24 & 1711.088 & 1711.088 & 1711.088 & 1711.088 & 0 \\
BM23 & 1714.160 & 1714.160 & 1714.160 & 1714.160 & 0 \\
BM21 & 1719.411 & 1719.411 & 1719.411 & 1719.411 & 0 \\
SBY015 & 1724.541 & 1724.962 & 1724.635 & 1724.713 & 0.221 \\
BM8 & 1716.635 & 1716.635 & 1716.635 & 1716.635 & 0 \\
LB08 & 1718.409 & 1718.371 & 1718.409 & 1718.396 & 0.022 \\
BM ITS01 & 1718.325 & 1718.325 & 1718.352 & 1718.334 & 0.016 \\
BM & 1718.352 & 1718.352 & 1718.352 & 1718.352 & 0 \\
Pakuwon & 1707.088 & 1707.729 & 1707.317 & 1707.378 & 0.325 \\
BM19 & 1708.430 & 1708.430 & 1708.545 & 1708.468 & 0.066 \\
LB01 & 1703.995 & 1703.995 & 1704.055 & 1704.015 & 0.035 \\
SBY003 & 1718.810 & 1718.810 & 1718.810 & 1718.810 & 0 \\
BMG.1.0324 & & & & \\
\hline \hline & & & & & \\
\hline
\end{tabular}

Tabel 2.

\begin{tabular}{cccc}
\multicolumn{4}{c}{ Konversi Bacaan Alat } \\
\hline \hline No & Stasiun & $\begin{array}{c}\text { Rata- } \\
\text { rata } \\
\text { bacaan }\end{array}$ & $\begin{array}{c}\text { Gayaberat } \\
\text { Relatif } \\
\text { (mGal) }\end{array}$ \\
\hline 1 & BMG.1.0324 & 1719.030 & 1743.20889 \\
2 & BM 16 & 1719.282 & 1743.46411 \\
3 & LB06 & 1726.005 & 1750.28245 \\
4 & BM01 & 1713.372 & 1737.47094 \\
5 & LB04 & 1706.440 & 1730.44099 \\
6 & SBY007 & 1714.222 & 1738.33295 \\
7 & BM33 & 1711.520 & 1735.59277 \\
8 & BM29 & 1714.141 & 1738.25081 \\
9 & BM24 & 1711.088 & 1735.15467 \\
10 & BM23 & 1714.160 & 1738.27008 \\
11 & BM21 & 1719.411 & 1743.59527 \\
12 & SBY015 & 1724.713 & 1748.97185 \\
13 & BM8 & 1716.635 & 1740.78005 \\
14 & LB08 & 1718.396 & 1742.56627 \\
15 & BM ITS01 & 1718.334 & 1742.50305 \\
16 & BM Pakuwon & 1718.352 & 1742.52131 \\
\hline
\end{tabular}

\begin{tabular}{lccc}
\hline 17 & BM19 & 1707.378 & 1731.39225 \\
18 & LB01 & 1708.468 & 1732.49799 \\
19 & SBY003 & 1704.015 & 1727.98173 \\
20 & BMG.1.0324 & 1718.810 & 1742.98578 \\
\hline \hline
\end{tabular}

Nilai standar deviasi yang didapatkan melambangkan tingkat presisi pengukuran. Semakin tinggi nilai standar deviasi maka tingkat presisinya semakin rendah. Pada tabel 4.3 di atas dapat dilihat bahwa nilai standar deviasi tinggi adalah SBY015 dan BM19 yaitu 0.22098 dan 0.32482. Nilai standar deviasi SBY015 (dekat Pergudangan) tinggi disebabkan karena aktivitas transportasi di area tersebut tinggi. Sedangkan, pada BM19 (dekat Wisata Mangrove) disebabkan lokasi patok yang sangat dekat dengan jalan, kondisi tanah disekitar patok yang kurang stabil dan beberapa kendaraan lalu lalang melewati jalan tersebut. Hasil konversi bacaan alat di lapangan dapat dilihat pada tabel 2.

\section{B. Drift Correction}

Hasil perhitungan koreksi apungan dapat dilihat pada tabel 3.

Tabel 3. Koreksi Apungan

\begin{tabular}{ccccc}
\hline \hline Stasiun & $\begin{array}{c}\text { Waktu } \\
\text { Pengukuran }\end{array}$ & $\begin{array}{c}\text { Selisih } \\
\text { Waktu } \\
\text { (jam) }\end{array}$ & $\begin{array}{c}\text { Drift } \\
\text { Correction } \\
\text { (mGal) }\end{array}$ & $\begin{array}{c}\text { g_rel } \\
\text { terkoreksi }\end{array}$ \\
\hline BMG.1.0324 & $23: 04: 30$ & $0: 00: 00$ & 0.000 & 1743.209 \\
BM 16 & $23: 28: 37$ & $0: 24: 07$ & 0.005 & 1743.469 \\
LB06 & $0: 04: 30$ & $1: 00: 00$ & 0.013 & 1750.295 \\
BM01 & $2: 05: 00$ & $3: 00: 30$ & 0.038 & 1737.509 \\
LB04 & $2: 25: 03$ & $3: 20: 33$ & 0.042 & 1730.484 \\
SBY007 & $2: 54: 15$ & $3: 49: 45$ & 0.049 & 1738.381 \\
BM33 & $3: 39: 00$ & $4: 34: 30$ & 0.058 & 1735.651 \\
BM29 & $4: 07: 15$ & $5: 02: 45$ & 0.064 & 1738.315 \\
BM24 & $4: 37: 35$ & $5: 33: 05$ & 0.071 & 1735.234 \\
BM23 & $5: 18: 20$ & $6: 13: 50$ & 0.079 & 1738.349 \\
BM21 & $6: 17: 21$ & $7: 12: 51$ & 0.092 & 1743.687 \\
SBY015 & $7: 57: 38$ & $8: 53: 08$ & 0.113 & 1749.085 \\
BM8 & $8: 32: 38$ & $9: 28: 08$ & 0.120 & 1740.901 \\
LB08 & $9: 12: 20$ & $10: 07: 50$ & 0.129 & 1742.695 \\
BM ITS01 & $10: 10: 45$ & $11: 06: 15$ & 0.141 & 1742.644 \\
BM Pakuwon & $10: 51: 50$ & $11: 47: 20$ & 0.150 & 1742.671 \\
BM19 & $12: 22: 55$ & $13: 18: 25$ & 0.169 & 1731.562 \\
LB01 & $13: 52: 45$ & $14: 48: 15$ & 0.188 & 1732.686 \\
SBY003 & $15: 06: 20$ & $16: 01: 50$ & 0.204 & 1728.186 \\
BMG.1.0324 & $16: 35: 42$ & $17: 31: 12$ & 0.223 & 1743.209 \\
\hline \hline
\end{tabular}

Nilai koreksi pergeseran dipengaruhi oleh waktu, sehingga dapat dilihat pada tabel 4.3 di atas bahwa semakin lama nilai koreksi pergeserannya semakin tinggi. Jika sudah terkoreksi pergeseran maka nilai gayaberat relatif dan gayaberat observasi awal dan akhir (BMG.1.0324) sama. 


\section{Free Air Reduction}

Hasil perhitungan reduksi udara bebas dapat dilihat pada Tabel 4.

Tabel 4. Reduksi Udara Bebas

\begin{tabular}{ccccc}
\hline \hline No & Stasiun & $\begin{array}{c}\text { Free Air } \\
\text { Reduction } \\
(\mathrm{mGal})\end{array}$ & $\begin{array}{c}\text { Anomali } \\
\text { Free Air } \\
(\mathrm{mGal})\end{array}$ & $\begin{array}{c}\text { Gayaberat } \\
\text { Geoid } \\
(\mathrm{mGal})\end{array}$ \\
\hline 1 & BMG.1.0324 & 1.543 & -3.4181 & 978110.303 \\
2 & BM16 & 1.061 & -4.2927 & 978110.0199 \\
3 & LB06 & 0.869 & 3.2795 & 978116.7027 \\
4 & BM01 & 2.418 & -8.2642 & 978105.4104 \\
5 & LB04 & 1.778 & -17.6798 & 978097.7116 \\
6 & SBY007 & 2.160 & -7.9176 & 978106.0927 \\
7 & BM33 & 3.064 & -9.5437 & 978104.1733 \\
8 & BM29 & 2.623 & -7.5009 & 978106.3489 \\
9 & BM24 & 8.160 & 1.0659 & 978108.8399 \\
10 & BM23 & 6.062 & 0.6959 & 978109.8772 \\
11 & BM21 & 2.371 & -0.7869 & 978111.6089 \\
12 & SBY015 & 0.666 & 1.6001 & 978115.3027 \\
13 & BM8 & 1.761 & -5.4588 & 978108.1092 \\
14 & LB08 & 0.933 & -4.9131 & 978109.1065 \\
15 & BM ITS01 & 1.014 & -5.5489 & 978109.1402 \\
16 & BM Pakuwon & 0.708 & -5.8422 & 978108.8598 \\
17 & BM19 & 0.806 & -17.6292 & 978097.8717 \\
18 & LB01 & 1.164 & -16.3243 & 978099.2841 \\
19 & SBY003 & 0.797 & -21.7607 & 978094.4681 \\
\hline \hline
\end{tabular}

\section{Plotting Data}

Penyajian data yang dilakukan dalam penelitian ini yaitu data anomali gayaberat free air data dan data anomali gayaberat free air EGM 2008 serta kombinasi data insitu dan data EGM. Berikut adalah hasil plotting data EGM 2008 untuk Kota Surabaya.

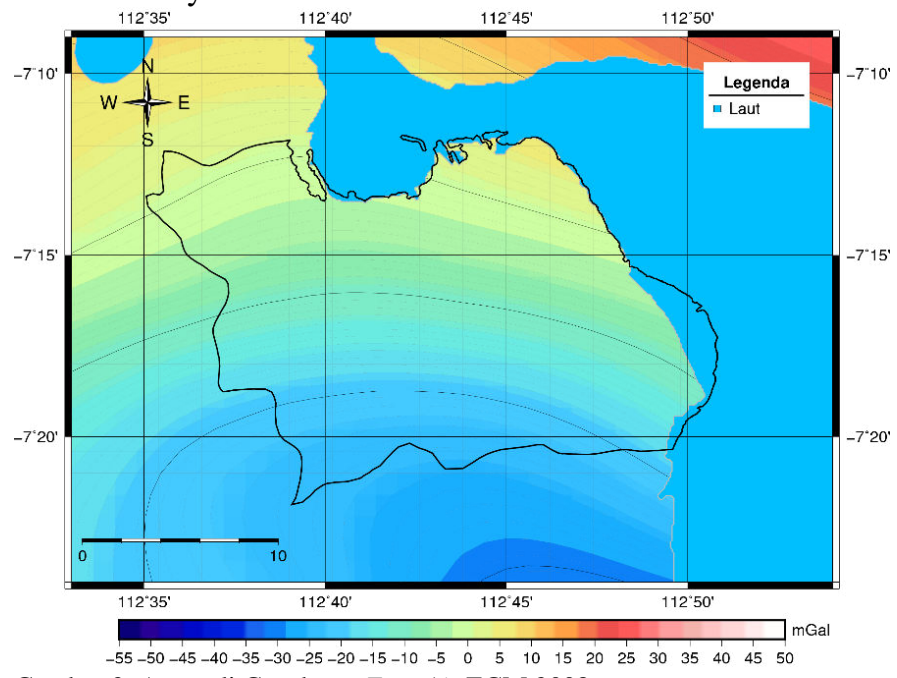

Gambar 3. Anomali Gayaberat Free Air EGM 2008.

Anomali free air EGM 2008 merupakan data yang telah digridkan dalam ukuran 2.5 menit $\times 2.5$ menit sehingga datanya cukup rapat. Dapat dilihat bahwa sebagian besar nilai anomali gayaberat free air Kota Surabaya memiliki nilai negatif (berwarna kebiruan).

Sedangkan hasil plotting data insitu Kota Surabaya dapat dilihat pada gambar 4 berikut.

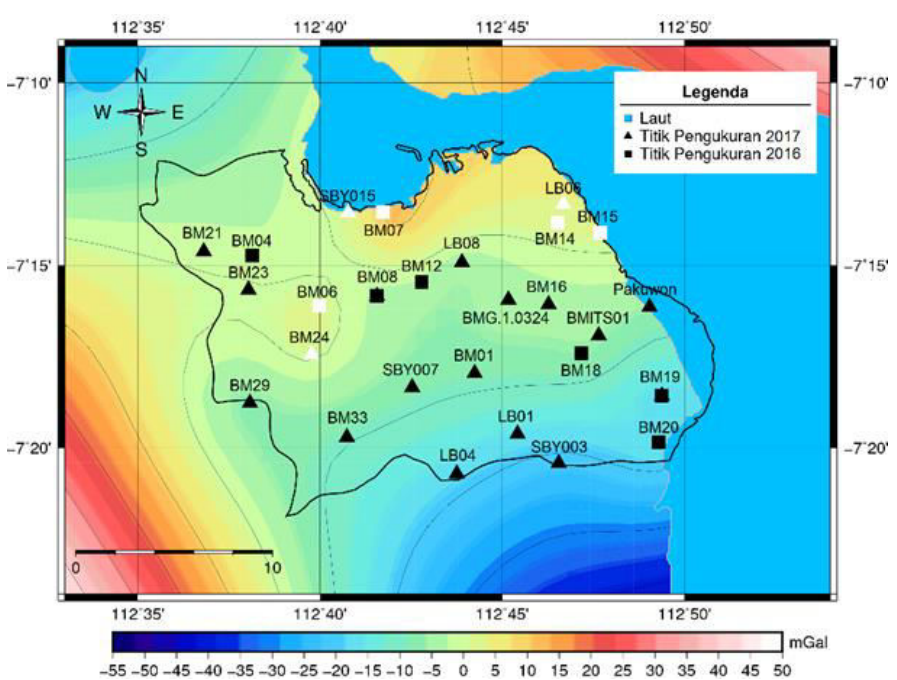

Gambar 4. Anomali Gayaberat Free Air Insitu.

Pada gambar 4 di atas dapat dilihat setelah penggabungan terdapat 28 titik pengukuran gayaberat. Titik pengukuran gayaberat ditunjukkan dengan tanda segitiga. Dapat dilihat bahwa data insitu memiliki nilai anomali yang lebih bervariasi. Jika dibandingkan dengan penyajian data EGM 2008 terdapat perbedaan yang sangat signifikan pada kedua gambar. Data insitu yang memiliki nilai anomali lebih bervariasi menjadikan peta yang lebih detail dan lebih teliti dibandingkan dengan data EGM 2008.

\section{KESIMPULAN}

Berdasarkan pengolahan dan analisis data yang telah dilakukan, berikut adalah kesimpulan yang penulis dapatkan dalam penulis studi ini.

1. Gayaberat free air di Kota Surabaya berkisar 978094.4681 mGal hingga $978116.7027 \mathrm{mGal}$, dengan anomali berkisar antara $-25 \mathrm{mGal}$ hingga $20 \mathrm{mGal}$. Berdasarkan data tersebut didapatkan bahwa nilai anomali gayaberat free air Kota Surabaya yang sangat bervariasi.

2. Anomali gayaberat free air yang didapatkan di Kota Surabaya berkisar antara $-30 \mathrm{mGal}$ hingga $10 \mathrm{mGal}$. Berdasarkan data tersebut didapatkan bahwa setengah dari wilayah Kota Surabaya memiliki anomali gayaberat free air yang kecil (kurang dari 0).

3. Hasil pengukuran gayaberat di lapangan menghasilkan nilai anomali gayaberat free air yang lebih bervariasi dibandingkan dengan anomali gayaberat free air EGM 2008.

\section{UCAPAN TERIMAKASIH}

Penulis E. S. mengucapkan terima kasih kepada Laboratorium Geodesy dan Surverying dan Geosolution yang telah menyediakan alat GPS pada pengukuran posisi 
horizontal serta Laboratorium Geofisika Jurusan Fisika Universitas Brawijaya yang telah menyediakan gravimeter untuk penelitian ini.

\section{DAFTAR PUSTAKA}

[1] I. M. Anjasmara, Modul Ajar Hitung Kerangka Geodesi. Surabaya, 2005.

[2] G. Rakapuri and et al, "Pemodelan Geoid Lokal Universitas
Diponegoro Semarang," J. Geod. UNDIP, pp. 15-21.

[3] N. K. Pavlis and et al, "The Development and Evaluation of The Earth Gravitational Model 2008 (EGM2008)," J. Geophys. Res., vol. 117, pp. 1-38, 2008.

[4] S. Maryanto and et al, "Pedoman Praktikum Workshop Geofisika," Malang, 2016.

[5] I. B. Osazuwa, "Cascade Model for the Removal of Drift from Gravimetric Data," Surv. Rev., vol. 29, pp. 295-303, 1988.

[6] B. Hoffman and H. Moritz, Physical Geodesy. New York: Springer, 2005. 